\title{
Body Image Perception and the Effectiveness of a Body Image Education in Pregnant Housewives
}

\author{
Melek Ardahan ${ }^{1 *}$ and Ayla Bayık Temel ${ }^{2}$ \\ ${ }^{1}$ Associate Professor, Department of Public Health, Faculty of Nursing, Ege University, Bornova-Izmir, Turkey. \\ ${ }^{2}$ Professor, Department of Public Health, Faculty of Nursing, Ege University, Bornova-Izmir, Turkey.
}

*Corresponding author : Melek ardahan, Associate Professor, Department of Public Health, Faculty of Nursing, Ege University, Bornova-Izmir, Turkey, Tel: 0090.232.3881103/5568; Fax: 0090.232.3886374; E-mail: melekardahan@hotmail.com, melek.ozer.ardahan@ege.edu.tr

Received date: March 14, 2014, Accepted date: May 03, 2014, Published date: May 07, 2014

Copyright: $\odot 2014$ Ardahan M, et al. This is an open-access article distributed under the terms of the Creative Commons Attribution License, which permits unrestricted use, distribution, and reproduction in any medium, provided the original author and source are credited.

\author{
Abstract \\ Background: Gestation and birth are physiological events and it might be easier for a woman to accept changes \\ in her body image resulting from changes occurred in her body.
}

Purpose: This study aims to determine body alterations, thoughts and behaviors of pregnant women which reflect their body image, and evaluate the effectiveness of education.

Methods: The data for the intervention research was collected through face to face interviews conducted with 39 volunteer women who applied to health centers with the use of 36-item "Body Image in Pregnant Women Form". In examination of data, t-test is used. The study approvals of relevant institutions are obtained.

Results: The body and image satisfaction of pregnant before the pregnancy was $97.4 \%$, whereas it is $84.6 \%$ during pregnancy. In statistical analyses measuring the difference between the desire of eating $(t=5.783 p<0.01)$, the habit of looking at the mirror $(t=2.041 p<0.05)$, weigh checking behavior $(t=5.818 p<0.01)$, behavior of calling themselves names $(t=4.638 \mathrm{p}<0.01)$ pre-gestation and during gestation, a significant relationship was determined. All of the respondents stated that they were satisfied with the education and the subjects of training were beneficial.

Conclusion: When the results of the study examined, it was concluded that body image was changed during pregnancy, the pregnant were happy despite the alterations in body image, the education made contribution to the improvement of body image by changing the behaviors reflecting the body image.

Keywords: Body image; Pregnancy and Image; Education; Behavior; Turkey

\section{Introduction}

Leading psychopathologists from Kraepelin and Bleuler to the present have described schizophrenics' deviant perceptions, feelings, and beliefs concerning their bodies. Every experienced clinician has encountered schizophrenics who report delusions of rotting organs or changed sex, or perceptions of alterations in the size an shape of their bodies, or feelings of unreality of the body, of the merging of the body with external objects, and of the body not being one's own [1,2]. These experiences have come to be described as disturbances of the body image. Body image aberration plays an important role in Blatt and Wild's (1976) theorizing about schizophrenic disturbances in the capacity to establish and maintain boundaries. Theses writers explain not only body-image aberration but also disturbances of cognitive, perceptual, and interpersonal functioning in terms of this unifying construct [3]. Both Schilder [4] and Szasz [5] extended the concept of body image to a much wider range of phenomena, but we will use it here to refer only to deviant perceptions, feelings, and beliefs about one's own body. An individual's body image includes their skills, limitations, perceptions, and personal characteristics in addition to their conscious and unconscious behaviors towards their own body.
These behaviors cover the feelings related to size, function, appearance as well as perceptions pertaining to the past and the present [6]. The concept of body image is a dynamic process; starting from babyhood, acquiring a shape under the effects of socio-cultural events parallel to various physiological changes and then becomes an important part of the self via integration with the self $[7,8]$.

Body image is the picture formed in the human brain and this picture might be right or wrong. Different cultures have various ideas about the body. Therefore, body image alters just as the body itself changes over time. The women body can change due to, for example, sickness, old age, and gestation; it can even change in one month. The woman can perceive herself as bloated like a balloon as her monthly menstruation period approaches whilst slim at other times [6,9]. The psychology, behaviors, self-respect, and the concept of integrity of the individual are all effective in the body image change [10].

Self-image is identified with body image for many women. If she looks good, this is fine and obtaining an external acknowledgement is more important than her physical ego and internal pleasure [11]. The reaction that women have to their image at the mirror is affected by many factors such as sex, age, ethnical group, sexual orientation, emotional status, nutrition disorders, the television programmer watched, and marital status [11]. In addition, the following would also affect their emotions when they evaluate their appearance: how they 
Page 2 of 8

spent their childhood, whether they exercise or not, which period of menstrual cycle they are in, whether pregnant or not, the time when they just returned from shopping and even what they ate their last the meal. The body image of a woman is affected by various factors: Being extremely overweight or underweight, gestation (temporary physiological change), menopause, infertility, skin illnesses and wound scars, effluxion (feeling that her body is dirty and thus, creating a feeling of guilt), and body odor are amongst these $[7,8]$. Duncombe et al. [12] examined body image across pregnancy and reported that body image was found to be fairly stable across pregnancy such that women who started with greater body concerns maintained them over time. Women with the most body concerns reported more depressive symptoms, tendency towards dieting, and smoking during pregnancy suggesting they were at greater risk in terms of health and well-being during pregnancy.

Perceiving the body differently is more common in pregnant women. The increase in the body weight during gestation followed by abdomen's noticeable shape causes many women to feel heavy, awkward, and unattractive while their movements become clumsy and their coordination can be affected. In addition, the posture of women changes, their self-confidence can decrease, thus their body image could be affected negatively [13-15]. Although body shape changes less in the 1st trimester, as the gestation progresses changes occur; the enlargement of the abdomen, thickening of waist, and increasing size of the breasts. As gestation progresses, the responses of the family and friends to these changes may also increase in addition to that of the pregnant woman $[13,14,16,17]$. Some of the common body image perceptions that a pregnant woman may have like "I looked at the mirror and I was surprised, was that really me? I got a sudden feeling that I was just like a balloon in appearance. I wondered how I would cope with this and would I be myself again." Changes in the perception of body limits occur in pregnant women. This change in the perception of limits is so strong that pregnant women can move away from some objects, for example, a pregnant woman can take a protective position while approaching a table [6].

Psychological changes occur during pregnancy. One of very evident changes is also increase in weight. The ability to accept this change depends especially on emotional stability, food, smoking and job of pregnant women [18]. Women who exercise during pregnancy may respond more favorably to changes in their bodies at early pregnancy compared to women who remain sedentary [19].

Gestation and birth are physiological events and it might be easier for a woman to accept changes in her body image resulting from changes occurred in her body, cope with many problems, and adapt to this new situation through external support in this period. In these issues, nurses have significant responsibilities in terms of psychological support and training [20]. But, regular training programs for pregnant woman's body image don't carry out in Turkey. Only the pregnant women for the control to the hospital or village clinic describe needs to do for a healthy pregnancy. Because of this, I want to carry out regular training programs. Also, I think their effectiveness and benefits. This study aims to determine body image perception and the effectiveness of a body image education in pregnant housewives.

\section{Methods}

\section{Sample}

This study was conducted at Evka-3 Village Clinic and Ataturk Village Clinic under the authority of Izmir Bornova Health Group Presidency. The data for the intervention research was collected through face to face interviews conducted with 39 volunteer women who applied to health centers with the use of 36-item "Body Image in Pregnant Women Form".

Of the pregnant women group $92.4 \%$ were in the 15-34 age groups, with an average age of $25.92 \pm 4.93$. The minimum age of pregnant women was 15 , whereas the maximum age was 45 . Of these pregnant women, $2.6 \%$ were not literate, $41.0 \%$ had only completed primary school, $10.3 \%$ had finished secondary school, $41.0 \%$ had completed their high school education, $5.1 \%$ were university graduates, and $100.0 \%$ were unemployed.

\section{Instruments}

A questionnaire about body image in pregnant women with 36 questions was prepared by researchers. Six questions referred to sociodemographic characteristics of pregnant women, four questions on the changes occurring in the body of women during gestation, eight questions on the perceptions of pregnant women about gestation and health levels an evaluation of weight gain in gestation was achieved through ten questions, and eight questions were define body image, behaviors and thoughts that reflect the body image of pregnant women.

Moreover, the effectiveness of the education was evaluated with six extra questions. The pregnant women were asked whether they were satisfied with the education, which subjects were the most useful, what they would like to learn if they were offered another education, to what extent the subjects explained were useful, if there were any changes of behavior caused by the subjects explained and the patterns of behavior they developed according to body alterations.

A pilot test was carried out in 10 pregnant women. Since a questionnaire was used for data collection, validity and reliability studies were not conducted. Data was collected through face-to-face interviews at village clinics.

\section{Data collection}

At the first meeting with pregnant women, the body image questionnaire was administered, situations were detected, and then the problems were determined. In light of the attained data, it was concluded that a training program was required for the pregnant women. Four-week training was carried out by the researchers, group training were made. The researchers were women and between the ages of 24-32. The training program covered topics such as gestation physiology, changes seen in gestation, coping with problems during gestation, and how to achieve a healthy gestation (weight control, exercising, nutrition, emotional changes, and accepting the pregnancy) This was followed by a planned training program for the pregnant women directed towards positively affecting body image of pregnant women and developing positive health behaviors; training programs were conducted at both village clinics for four weeks once a week for one hour. 
Page 3 of 8

On the last day of the training, the pregnant women were asked to go to the clinics again one week later. One week later, the opinions of pregnant women were taken regarding their satisfaction with the training, benefits of the training, and whether the information they obtained through the training resulted in the development of positive behaviors in terms of their attitude towards their pregnant selves.

All pregnant housewives were received training. Because other pregnant women to join the training program was thought to be difficult.

\section{Ethical considerations}

Before the investigation, the necessary consent was obtained from the Ethics Committee of Ege University School of Nursing and Bornova Health Group Presidency. No limitation was put in selection of the pregnant women. The purpose and duration of the investigation was verbalized to pregnant women. In addition, the days that the training would take place were given and only the pregnant women volunteers who could meet these conditions were included in the investigation and training. Questions that would offend the pregnant women such as "Do you realize that you have gained weight when you look at the mirror?" or "Do you feel like a jumper?" were avoided. If the pregnant woman did not understand the question, the relevant question was reread slowly until she understood, so pregnant women were able to answer the questions correctly. The subjects have the right not to answer any question. Pregnant women were informed about any problems detected and then they were sent to relevant health institutions for further examination.

\begin{tabular}{|l|l|l|}
\hline & $\begin{array}{l}\text { EVKA-3 CLINIC } \\
\text { (Tuesdays ) }\end{array}$ & $\begin{array}{l}\text { ATATURK CLINIC } \\
\text { (Thursdays) }\end{array}$ \\
\hline $\begin{array}{l}\text { I. Week } \\
\text { Time:10.00-11.00 }\end{array}$ & Physiology in pregnancy & Physiology in pregnancy \\
\hline $\begin{array}{l}\text { II. Week } \\
\text { Time:10.00-11.00 }\end{array}$ & Changes during pregnancy & Changes during pregnancy \\
\hline $\begin{array}{l}\text { III. Week } \\
\text { Time:10.00-11.00 }\end{array}$ & $\begin{array}{l}\text { Coping with problems during } \\
\text { pregnancy }\end{array}$ & $\begin{array}{l}\text { Coping with problems during } \\
\text { pregnancy }\end{array}$ \\
\hline $\begin{array}{l}\text { IV. Week } \\
\text { Time:10.00-11.00 }\end{array}$ & $\begin{array}{l}\text { Principles for a healthy } \\
\text { pregnancy (weigt control, } \\
\text { exercise, nutrition, emotional } \\
\text { changes, accepting the } \\
\text { pregnancy ) }\end{array}$ & $\begin{array}{l}\text { Principles for a healthy } \\
\text { pregnancy (weigt control, } \\
\text { exercise, nutrition, emotional } \\
\text { changes, accepting the } \\
\text { pregnancy) }\end{array}$ \\
\hline
\end{tabular}

Table 1: Training Program

\section{Analysis}

Researchers coded data and their minimum-maximum consistency controls were performed. In evaluating those behaviors and thoughts related to image the pregnant women had of their bodies 1 point was assigned to the answer "often", 2 points to the answer "occasionally", 3 points to the answer "rarely", and 4 points to the answer "never". The data was broken down and calculated as numeric values, number and percentage distribution, averages and standard deviations, and t-test was performed using SPSS 16.0 software. Number-percentage analyses were conducted for the evaluation of the effectiveness of education, as well.

\section{Results}

Of the pregnant women $56.4 \%$ were in the first pregnancy, $28.2 \%$ were in the second pregnancy, 15.45 were in the third pregnancy and above. Of the pregnant women $10.3 \%$ were in the first trimester, 35.95 were in the second trimester, $53.8 \%$ were in the third trimester and the mean gestation week was $23.92 \pm 8.17$. Lastly, $87.2 \%$ of the women wanted to be pregnant, $12.8 \%$ with the remainder of the group stating that they did not want to be pregnant.

\section{Physical changes}

Of the pregnant women $87.2 \%$ stated that there had been changes in their body during pregnancy and only $12.8 \%$ stated the opposite. The first five changes that occurred in their body during gestation are as follows: weight gain (51.3\%), swollen breasts (43.6\%), stretch marks on the abdomen (20.5\%), swollen of hands and feet (17.9\%), heat burn/ indigestion, nausea /vomiting, and fatigue/lassitude (all with 15.4\%).

Of the pregnant women $51.3 \%$ stated that they are unhappy with the changes occurred in their body during gestation. The most disturbing changes were excess weight $(20.5 \%)$, pains (15.4\%), stretch marks on abdomen and swollen hands and feet (12.8\%), edema and nausea (7.7\%), and fatigue and heat burn (5.1\%). However, only $10.3 \%$ pregnant women stated that they would have aborted this pregnancy if they had known that these changes would happen.

\begin{tabular}{|l|l|l|}
\hline & Number (N) & Percent (\%) \\
\hline Changes & 34 & 87.2 \\
Yes & & \\
\hline No & 5 & 12.8 \\
\hline Physical changes & & \\
\hline Swollen breasts & 17 & 43.6 \\
Weight gain & 20 & 51.3 \\
Stretch marks on the abdomen & 8 & 20.5 \\
Swollen of hands and feet & 7 & 17.9 \\
Back pain & 5 & 12.8 \\
Backache & 3 & 7.7 \\
Groin pain & 2 & 5.1 \\
Dizziness & 4 & 10.3 \\
Heat burn/indigestion & 6 & 15.4 \\
Nausea /vomiting & 6 & 15.4 \\
Breast cracks & 3 & 7.7 \\
Fatigue/lassitude & 6 & 15.4 \\
Frequent urination & 1 & 2.6 \\
Changes in emotion & 1 & 2.6 \\
Varicosis & 1 & 2.6 \\
Edema & 2 & 5.1 \\
Stigma & 2 & 5.1 \\
Numbness in the arms & 1 & 2.6 \\
Craving & 1 & 2.6 \\
\hline Disturbing changes & 8 & 15.4 \\
\hline Excess weight & 6 & \\
Pains & 5 & \\
Stretch marks on abdomen & & \\
\hline & & \\
\hline
\end{tabular}




\begin{tabular}{|l|l|l|}
\hline Swollen hands and feet & 5 & 12.8 \\
Edema & 3 & 7.7 \\
Nausea/vomiting & 3 & 7.7 \\
Fatigue /lassitude & 2 & 5.1 \\
Heat burn/indigestion & 2 & 5.1 \\
\hline
\end{tabular}

Table 2: Physical changes in pregnant women

When the pregnant women were asked whether they attempted to prevent or remove the changes in their bodies, $46.2 \%$ stated that they did something however, only $30.8 \%$ of the pregnant women stated that they actually knew what to do. $94.9 \%$ of pregnant women wanted to learn what they could do to alleviate the changes. While $35.9 \%$ of pregnant women wanted to know everything about pregnancy, $20.5 \%$ wanted to know about nutrition $17.9 \%$ wanted to know about nutrition for weight control and baby care, $12.8 \%$ wanted information about the preparation to the delivery, and $10.3 \%$ for the methods of alleviating the pain of pregnancy.

\section{The perception of health}

While $20.5 \%$ of the pregnant women stated that their health level was very good pre-gestation, $61.5 \%$ expressed it as good and $18.0 \%$ as moderate. During gestation, however, $7.6 \%$ expressed their health level as very good and $46.2 \%$ as good and moderate.

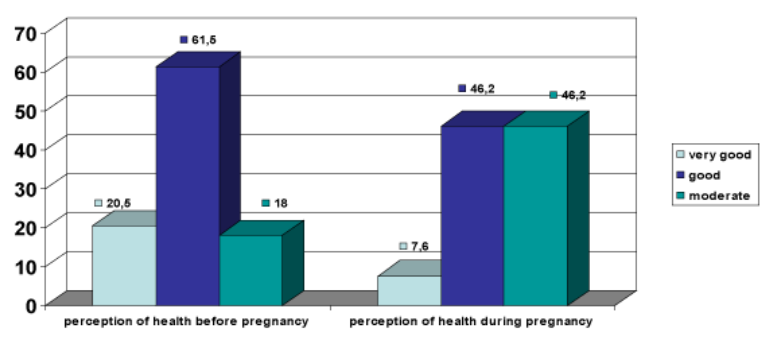

Figure 1: The perception of health in pregnant women.

\section{The perception of happiness}

Of all the pregnant women in the study group, $61.5 \%$ were very happy with their lives in general while $38.5 \%$ were moderately happy

\section{The views of pregnant women on gestation}

When pregnant women were asked about their thoughts on gestation, $7.7 \%$ said "I am getting fat, my body lost its shape", 53.8\% said "Although my body lost its shape in pregnancy, it is nice, exciting", 30.8 \% said "Both", and 7.7\% said, "I have no idea."

\section{The views of pregnant women on their body appearances}

Of the pregnant women group $97.4 \%$ expressed that they were happy with their body and appearance pre-gestation while $2.6 \%$ expressed the opposite for the pre-gestation period. It was determined that $64.1 \%$ of pregnant women did not think to lose weight pregestation. Of the pregnant women attempted reducing weight pregestation, $15.4 \%$ tried diet and exercise and $10.3 \%$ tried eating less and giving up eating bread, pastry and cakes. Of the pregnant women $20.5 \%$ wanted to gain weight before pregnancy. Because pregnant women have a thin body. For this reason, $10.0 \%$ of the pregnant women spent less energy, $5.1 \%$ ate more than usual, and $2.6 \%$ ate sweet food and took vitamins to gain weight.

Of pregnant women $46.2 \%$ stated that they found other pregnant women more overweight than themselves whilst $30.8 \%$ found other pregnant women less overweight than themselves. The mean weight of pregnant women was $56.41 \mathrm{~kg} \pm 9.66$ at the time of becoming pregnant. The mean weight gain of pregnant women at the 1st trimester was detected as $5.55 \mathrm{~kg}$ with $7.55 \mathrm{~kg}$ and $11.90 \mathrm{~kg}$ at the 2nd and $3 \mathrm{rd}$ trimesters respectively. The general average weight gain of pregnant women during pregnancy was $8.74 \mathrm{~kg} \pm 4.71$.

\section{Behaviors and thoughts about body image}

Of pregnant women \%78.9 defined body image. Pre-gestation $7.7 \%$ of pregnant women frequently thought about and this rate increased to $41.0 \%$ during gestation. In statistical analyses measuring the desire of eating pre-gestation and during gestation, a very sound significant relationships was found $(t=5.783 \quad \mathrm{p}<0.01)$. While the number of women looking in the mirror frequently was $17.9 \%$ pre-gestation, this rate increased to $35.9 \%$ during pregnancy. In the statistical analysis measuring the difference between the habit of looking at the mirror pre-gestation and during gestation, a significant relationship was determined $(\mathrm{t}=2.041 \mathrm{p}<0.05)$. While at pre-gestation $12.8 \%$ of pregnant women weighed themselves frequently, during pregnancy $46.2 \%$ stated that they checked their weight more frequently. In the statistical analysis directed towards weigh checking behavior pregestation and during gestation a quite significant relationship was detected $(t=5.818 \quad \mathrm{p}<0.01)$. While only $2.6 \%$ of women frequently called themselves names such as fat, pre-gestation, this rate increased to $20.5 \%$ during gestation. In the statistical analysis of pre- and during gestation behavior of calling themselves names, a quite significant relationship was found $(t=4.638 \mathrm{p}<0.01)$. Of study participants $15.4 \%$ wanted to eat cakes, pastries and candy pre-gestation and this rate slightly increased to $20.5 \%$ during gestation. However, no statistical significant relationship was detected between the desire to eat sweet food pre-gestation and during gestation $(\mathrm{t}=0.259 \mathrm{p}>0.05) .12 .8 \%$ of the study group pregnant women were exercising pre-gestation, this rate increased to $20.5 \%$ during gestation. In the analysis directed towards the habit of sports pre-gestation and during gestation no significant relationship was detected $(t=0.892 \mathrm{p}>0.05)$. It is thought that the body image is not affected due to the low number of women who exercise before and during pregnancy. While $17.9 \%$ of pregnant women thought of their physical appearance pre-gestation, $28.2 \%$ do the group stated that they thought about their appearance during gestation. Nevertheless, no significant relationship was found pregestation and during gestation in terms of thinking of appearance.

Of pregnant women, $43.6 \%$ had the habit of walking and exercising. When the frequency of walking and exercising was asked, $30.8 \%$ responded "everyday," $10.3 \%$ "every other day," and $5.1 \%$ "occasionally". 
Citation: Ardahan M, Temel AB (2014) Body Image Perception and the Effectiveness of a Body Image Education in Pregnant Housewives. J Nurs Care 3: 163. doi:10.4172/2167-1168.1000163

Page 5 of 8

\begin{tabular}{|c|c|c|c|c|c|c|c|c|c|c|c|c|c|c|c|c|c|}
\hline \multicolumn{8}{|c|}{ Pre-Gestation } & & \multicolumn{9}{|c|}{ Post-Gestation } \\
\hline \multicolumn{2}{|c|}{ Often } & \multicolumn{2}{|c|}{ Occasionally } & \multicolumn{2}{|c|}{ Rarely } & \multicolumn{2}{|c|}{ Never } & & \multicolumn{2}{|c|}{ Often } & \multicolumn{2}{|c|}{ Occasionally } & \multicolumn{2}{|c|}{ Rarely } & \multicolumn{2}{|c|}{ Never } & \\
\hline No & $\%$ & No & $\%$ & No & $\%$ & No & $\%$ & & No & $\%$ & No & $\%$ & No & $\%$ & No & $\%$ & \\
\hline 3 & 7.7 & 9 & 23.1 & 10 & 25.6 & 17 & 43.6 & $\begin{array}{l}\text { I think about } \\
\text { eating.( can't put } \\
\text { "always" because } \\
\text { of your - often } \\
\text { occasionally rarely } \\
\text { never criteria) }\end{array}$ & 16 & 41.0 & 16 & 41.0 & 4 & 10.3 & 3 & 7.7 & $\begin{array}{l}t=5.783 \\
p<0.01\end{array}$ \\
\hline 7 & 17.9 & 12 & 30.8 & 15 & 38.5 & 5 & 12.8 & $\begin{array}{l}\text { I look in the mirror } \\
\text { very often. }\end{array}$ & 14 & 35.9 & 14 & 35.9 & 7 & 17.9 & 4 & 10.3 & $\begin{array}{l}t=2.041 \\
p<0.05\end{array}$ \\
\hline 5 & 12.8 & 8 & 20.5 & 14 & 35.9 & 12 & 30.8 & $\begin{array}{l}\text { I weigh myself } \\
\text { very often. }\end{array}$ & 18 & 46.2 & 12 & 30.8 & 9 & 23.1 & & & $\begin{array}{l}t=\quad 5.818 \\
p<0.01\end{array}$ \\
\hline 1 & 2.6 & 2 & 5.1 & 11 & 28.2 & 25 & 64.1 & $\begin{array}{l}\text { I call myself } \\
\text { names such as fat }\end{array}$ & 8 & 20.5 & 11 & 28.2 & 6 & 15.4 & 14 & 35.9 & $\begin{array}{l}t=4.638 \\
p<0.01\end{array}$ \\
\hline 6 & 15.4 & 10 & 25.6 & 11 & 28.2 & 12 & 30.8 & $\begin{array}{l}\text { I have desire to } \\
\text { eat sweets, a slice } \\
\text { of cake, etc. }\end{array}$ & 8 & 20.5 & 9 & 23.1 & 9 & 23.1 & 13 & 33.3 & $\begin{array}{l}t=0.259 \\
p>0.05\end{array}$ \\
\hline 5 & 12.8 & 12 & 30.8 & 12 & 30.8 & 10 & 25.6 & $\begin{array}{ll}\text { I perform light } \\
\text { sports } & \text { like } \\
\text { walking, } & \\
\text { exercising etc. }\end{array}$ & 8 & 20.5 & 12 & 30.8 & 11 & 28.2 & 8 & 20.5 & $\begin{array}{l}t=0.892 \\
p>0.05\end{array}$ \\
\hline 7 & 17.9 & 15 & 38.5 & 8 & 20.5 & 9 & 23.1 & $\begin{array}{l}\text { I think about the } \\
\text { appearance of my } \\
\text { body. }\end{array}$ & 11 & 28.2 & 14 & 35.9 & 7 & 17.9 & 7 & 17.9 & $\begin{array}{l}t=1.157 \\
p>0.05\end{array}$ \\
\hline
\end{tabular}

Table 3: Review of behaviors and thoughts that reflect body image of the pregnant woman

When the dietary habits that would be effective in improving the body images and appearance of the pregnant women were evaluated, $64.1 \%$ indicated that their appetite was good, $28.2 \%$ as moderate, and $7.7 \%$ as poor. The rate of those who controlled their food consumption was $59 \%$. When the way they controlled their consumption was examined, it was determined that $10.3 \%$ ate frequently and consumed vegetables and fruit, $12.8 \%$ avoided pastry, $7.7 \%$ did not eat excessively and avoided harmful foods (cola, salt, coffee, sugar), and $5.1 \%$ paid attention to eating breakfast and did not think about eating by committing herself to housework. Moreover, it was determined that pregnant women drank $6.23 \pm 2.68$ glasses of water per day on average where the habit of defecating was good in $4.1 \%$, moderate in $51.3 \%$, and poor in $7.7 \%$ of pregnant women.

\section{Post-training evaluation of the pregnant women regarding the training program}

All the pregnant women from the study group participated in the training program and stated that they were happy with the training. Of pregnant women, $41.0 \%$ expressed that all the topics covered were beneficial, $23.1 \%$ expressed that the topic of a healthy gestation was beneficial, $15.4 \%$ expressed that the topic of issues encountered during gestation and the methods of coping with them was beneficial, $12.8 \%$ expressed that the topic of gestation physiology was beneficial, and 7.7\% expressed that the topic of changes seen in gestation was beneficial. When the pregnant women were asked what else they wished to learn if another training were conducted, $46.2 \%$ wanted the repetition of the same topics, $17.9 \%$ wanted the topics of baby care and overcoming the fear of delivery, $15.4 \%$ wanted information baby nourishment, baby growth, preparation for delivery, problems to be encountered during delivery, and post-delivery exercises, and $7.7 \%$ wanted to know what to do after delivery.

On the last day of the training, the pregnant women were asked to go to the clinics again one week later. One week later, the study group were asked to what extent were the covered topics beneficial, $61.5 \%$ stated that they were "very useful," $38.5 \%$ stated they were "useful," and $76.9 \%$ stated they believed the relevant information would create a change in their behavior. Following the training, most of pregnant women developed some new or modified behavioral patterns related to the changes occurred in their body. These patterns can be seen on Table 4.

\begin{tabular}{|l|l|}
\hline Physical Changes & Behavioral Patterns \\
\hline Breast Sensitivity & - Using a bra that provides a good support \\
\hline Weight Gain & $\begin{array}{l}\text { - Paying attention to diet } \\
\text { - Walking and exercising } \\
\text { - Drinking water }\end{array}$ \\
\hline Stretch marks on abdomen & $\begin{array}{l}\text { - Using almond oil } \\
\text { - Keeping the abdominal area clean and } \\
\text { massaging that area }\end{array}$ \\
\hline Swollen hands and feet & $\begin{array}{l}\text { - Limiting the use of salt } \\
\text { - Drinking ample water and going to the toilet } \\
\text { frequently }\end{array}$ \\
\hline Back pain & $\begin{array}{l}\text { - Paying attention to not sitting for too long, } \\
\text { getting up, and walking }\end{array}$ \\
\hline
\end{tabular}




\begin{tabular}{|c|c|}
\hline & $\begin{array}{l}\text { - Sitting with legs slightly aloft and not crossing } \\
\text { legs } \\
\text { - Exercising } \\
\text { - Lying and resting in the position where knees } \\
\text { and hip are bent }\end{array}$ \\
\hline Lumbago & $\begin{array}{l}\text { - Resting by lying down } \\
\text { - Exercising } \\
\text { - Arranging body position while sitting and getting } \\
\text { up } \\
\text { - Not lifting very heavy items }\end{array}$ \\
\hline Groin/crotch pain & $\begin{array}{l}\text { - Bathing with warm water } \\
\text { - Exercising and resting at frequent intervals } \\
\text { - Going to the doctor when the intensity of pain } \\
\text { increases }\end{array}$ \\
\hline Heartburn/indigestion & $\begin{array}{l}\text { - Eating small-portions at frequent intervals } \\
\text { - Avoiding bending forwards suddenly } \\
\text { - Avoiding fatty, spicy foods, and especially fried } \\
\text { foods } \\
\text { - Avoiding tea, coffee, and chocolate }\end{array}$ \\
\hline Nausea/vomiting & $\begin{array}{l}\text { - Eating small-portions at frequent intervals } \\
\text { - Eating salty food such as crackers } \\
\text { - Getting out of bed slowly } \\
\text { - Avoiding unpleasant odors and foods }\end{array}$ \\
\hline Fatigue/lassitude & $\begin{array}{l}\text { - Resting } \\
\text { - Exercising } \\
\text { - Eating food containing iron and protein }\end{array}$ \\
\hline Frequent urination & $\begin{array}{l}\text { Drinking some water before sleeping/lying down } \\
\text { - Urinate whenever it is needed and bending } \\
\text { forwards while urinating }\end{array}$ \\
\hline Varicosis & $\begin{array}{l}\text { - Putting a chair or stool under feet during resting } \\
\text { and sitting } \\
\text { - Not crossing legs } \\
\text { - Wearing support stockings or socks (elastic } \\
\text { stockings) }\end{array}$ \\
\hline $\begin{array}{l}\text { Spots/skin discoloration } \\
\text { pigmentation }\end{array}$ & $\begin{array}{l}\text { - Avoid exposing skin to strong sunlight } \\
\text { - Using protective sun-cream }\end{array}$ \\
\hline
\end{tabular}

Table 4: Post training behavioral patterns of the pregnant women in relation to the physical changes during gestation.

\section{Discussion}

It might be thought that gestation at a younger age, not having low level of education, not exceeding the mean ideal number of children $(2$ or 3), and wishing to be pregnant would all result in those pregnant women having a positive body image. When the literature is reviewed, it is seen that pregnancy at a young age, educational level and voluntary pregnancy have a positive impact on body image [15,21]. Strang and Sullivan [22] conducted to investigate postpartal women's behaviors toward their body image; these behaviors were then compared to their prepregnant and pregnant body image attitudes. The results indicated that multiparas felt more positive about their postpartum body image than did the primiparas; the women felt more positive about their prepregnant body image than about their postpartum body image. According to the study conducted, it is thought that the pregnant women might have been confronted with the situations that would influence body image and cause body alterations since approximately half of them were close to trimester. Skouteris et al. [16] examined changes in body image and predictors of body dissatisfaction during pregnancy. For the most part women reported adapting to the changes that occurred in their body; however, women were most likely to experience higher levels of body dissatisfaction in early to mid-second trimester. Findings related to predictors of body dissatisfaction revealed that both social and psychological factors contributed to body image changes in pregnancy [13].

During gestation, various psychological changes occur in the body over the three trimesters. Fatigue, nausea and vomiting, frequent urinating, breast sensitivity, headache, weight gain are seen in the 1st Trimester while pains and burning, skin changes, constipation, anemia, and weight gain are seen in the 2 nd Trimester. In the last Trimester, breathlessness, sleep disturbances, skin changes, hemorrhoids, urine leakage and weight gain are among the observed physical changes [14]. In this study, pregnant women stated that there had been changes in their body during pregnancy. According to the statements of the pregnant women, the first five changes that occurred in their body during gestation are as follows: weight gain, swollen breasts, stretch marks on the abdomen, swollen of hands and feet, heat burn/indigestion, nausea /vomiting, and fatigue/lassitude.

Zwelling [20] suggests that pregnant women find these changes in their body during gestation as appropriate and emphasizing their fertility and feminity (femaleness) whereas, others state that they are affected negatively by these changes. In this study, pregnant women stated that they are unhappy with the changes occurred in their body during gestation. The most disturbing changes were excess weight, pains, stretch marks on abdomen and swollen hands and feet, edema and nausea, and fatigue and heat burn. However, only $10.3 \%$ pregnant women stated that they would have aborted this pregnancy if they had known that these changes would happen. Fox and Yamaguchi [23] examined the relationship between prepregnancy body weight and body image change in primigravid women. Women who were overweight before pregnancy were more likely to have had a positive change in body image when they were at more than 30 weeks' gestation. Women who were normal weight before pregnancy were more likely to have had a negative change.

Changes occurring in the body during pregnancy are known to affect the body image. As can be seen the majority of pregnant women have the desire to learn about many areas of pregnancy which can be thought as a positive approach that should affect the way they think about their bodies in a positive way. When the change in the perception of heath in the pregnant women related to the pregestation and gestation period was examined, it is recognized that the level perceiving health decreases. This situation can be thought to be connected to the changes that occur in the gestation period.

Pregnant women are generally happy with their lives. Although most pregnant women thought their image of their bodies' image had been affected, their views related to gestation were positive. Jayasvasti and Kanchanatawan [21] examined happiness and related factors in pregnant women. Four predictive factors for happiness in pregnant women were extrovert personality, stable personality, high family income and improved marital relationship. According to a study by Fox and Yamaguchi in 1997, it was seen that the women who were within the normal weight range pre-gestation had a more negative 
body image during pregnancy whilst overweight women perceived their body image as positive [23]. When the height and weight standards of Turkish women as well as the height range of Turkish women, within $150 \mathrm{~cm}$ and $170 \mathrm{~cm}$, are taken into account in addition to the mean weight value of $56.41 \mathrm{~kg}$, it was thought that study group of pregnant women did not have corpulent bodies. When the relevant literature was reviewed, it is seen that average body weight increase of 9-15 kgs during pregnancy is stated as normal [24-27). When the trimesters are compared in terms of ideal weight increase values in pregnant women, it was concluded that monthly weight gain was healthy in the pregnant women in the study group. Dipietro et al.[15] examined pregnant women's weight-related behaviors and behaviors in relation to a constellation of psychosocial characteristics, pregnancy body habitus, and gestational weight gain. Women's behaviors about weight gain in pregnancy are imbedded in their orientation toward pregnancy as well as their general psychological functioning. Effective nutrition counseling for pregnant women should include consideration of weight-restrictive behaviors, the degree to which the pregnancy is perceived as positive and uplifting, and whether weight gain behaviors may be associated with their relationship with a spouse or partner. Bartosikova and Tyrlik [18] investigated perception of changes in body weight during pregnancy. In the whole set, $12 \%$ of women are concerned with their weight intensively and perception of their weight is rather negative. 5.8\% of women show negative relationship to pregnancy at the beginning, in the second trimester it is only the small fragment of all women. The reason for the negative perception of the weight is influenced by somatic, psychic and social aspects. The most important issue is emotional stability. The most common increase in weight was between $8-15 \mathrm{~kg}$, in average $11.34 \mathrm{~kg}$.

A literature review indicated that in various studies pregnant women were reported as feeling different and strange (fat, elephant, watermelon, ugly etc.) due to the body image change in gestation $[28,29]$. These studies demonstrated that physical activity increased the energy levels of women who exercised regularly during gestation and post-gestation in addition to increasing their morale, making them feel better, and causing them to look better [24]. In a study by Goodwin et al. in Australia [30], body image and the psychological situations of women who exercised during pregnancy were compared and marked differences were detected. Boscaglia et al. [19] aimed to compare ratings of body image satisfaction (BIS) from 6 months pregnancy to 23-30 weeks' gestation for high exercising and low exercising pregnant women. At 15-22 weeks' gestation, high exercisers demonstrated significantly higher levels of BIS compared to low exercisers. There were no other significant differences between groups. Within groups, high exercisers were significantly more satisfied with their bodies at 15-22 weeks' gestation compared to 6 months pregnancy, and expected to be less satisfied with their bodies at 6 weeks' post-partum than they were during pregnancy.

When the changes in the behaviors and thoughts of pregnant women that would affect their perception of their body are evaluated within this investigation, it can be stated that those behaviors related to health such as looking at the mirror frequently, checking their weight, walking and exercising, and thinking their appearance positively result in the women having a better body image whereas those behaviors and thoughts such as eating excessively sweet foods, over eating, and assuming nicknames might create a negative image of their body image $[31,32]$. When these values are considered, it appears that the frequency of exercising was insufficient since approximately one third of pregnant women in the study group were exercising everyday and this might generate some negative consequences for the pregnant women's health.

The training program covered topics such as gestation physiology, changes seen in gestation, coping with problems during gestation, and how to achieve a healthy gestation. All the pregnant women from the study group participated in the training program. The study was carried out with a small sample to ensure participation, to provide a more effective training and to improve patterns of behaviors. Since education was given throughout the research, only housewife could participate. Therefore, the research results can not be generalized for all pregnant women. But, following the training, most of pregnant women developed some new or modified behavioral patterns related to the changes occurred in their body. Because of this, this research gives outlook to further research needed for body image research and its implication for women's health during pregnancy in general.

\section{Limitation}

The limitation of the research is that 39 pregnant women were included in the research. The analyses were made after the required data was collected from the pregnant women. Training requirements of the pregnant women were determined in line with the acquired results. The study was carried out with a small sample to ensure participation, to provide a more effective training and to improve patterns of behaviors. Since education was given throughout the research, only housewife could participate. Therefore, the research results cannot be generalized for all pregnant women. Furthermore, pregnant women with chronic diseases were not included within the scope of the research considering that chronic diseases influence the body image in pregnant women.

\section{Conclusion}

In the study, approximately half of the pregnant women were in the 3rd trimester and the majority of pregnancies were wanting. The first five most common changes were weight gain, swollen breasts, stretch marks on the abdomen, swollen hands and feet, heat burn, nauseavomiting, and fatigue-lassitude. When the changes in behaviors and thoughts of pregnant women that would affect body image were evaluated, it can be stated that those behaviors related to health such as looking at the mirror frequently, checking their weight, walking and exercising, and thinking positively about their appearance, all have a positive affect on how the pregnant woman perceives her whereas, those behaviors such as eating excessively sweet foods, overeating, and thinking of themselves as "fat" and assuming other disapproving nicknames might affect their image of their bodies in a negative way.

As a consequence, it was concluded that pregnant women in the study group were generally happy despite the changes in the way they perceived their bodies during pregnancy, the training provided by nurses was reflected in behaviors of pregnant women, and lastly, that the training program was beneficial.

\section{Acknowledgements}

We would like to thank all the women who shared their opinion and practices with the research team. We also thank the Ethics Committee of Ege University School of Nursing and Bornova Health Group Presidency. 
Citation: Ardahan M, Temel AB (2014) Body Image Perception and the Effectiveness of a Body Image Education in Pregnant Housewives. J Nurs Care 3: 163. doi:10.4172/2167-1168.1000163

Page 8 of 8

\section{References}

1. Kraeplin E (1919) Dementia praecox and paraphrenia. Livingston Edinburgh.

2. Shenton ME1, Dickey CC, Frumin M, McCarley RW (2001) A review of MRI findings in schizophrenia. Schizophr Res 49: 1-52.

3. Blatt SJ, Wild CM (1976) Schizophrenia: A developmental approach. Academic Press, New York.

4. Schilder P (1935)The image and appearance of the human body. Kegan Paul, London.

5. Szasz TS (1957) The psychology of bodily feelings in schizophrenia. Psychosom Med 19: 11-16.

6. Erkal S, Pek H (1993) Changes in body image and role of the nurse. Nursing Journal. 7:61-71.

7. Cimete G (1993) Development of self-image and the woman. Turkish Journal of Nursing. 43:8-12.

8. Eti Aslan F (1996) Nursing approaches towards patients experiencing changes in body image. Turkish Journal of Nursing. 46:26-27.

9. Sirin A (2003) Reproduction health and body image. 3rd International Reproduction Health and Family-Planning Congress Book, Ankara.

10. Miller KD (1991) Body-image therapy. Nurs Clin North Am 26: 727-736.

11. Schmied V1, Lupton D (2001) The externality of the inside: body images of pregnancy. Nurs Inq 8: 32-40.

12. Duncombe D1, Wertheim EH, Skouteris H, Paxton SJ, Kelly L (2008) How well do women adapt to changes in their body size and shape across the course of pregnancy? J Health Psychol 13: 503-515.

13. Kocak F, Kukulu Km (1993) Exercise during pregnancy and puerperium period. Turkish Journal of Nursing. 43:13-14.

14. Bobak IM, Jensen MD (1987) Essentials of maternity nursing the nurse and the childbearing family. 2nd edition. Toronto: U.S.A.

15. Dipietro JA1, Millet S, Costigan KA, Gurewitsch E, Caulfield LE (2003) Psychosocial influences on weight gain attitudes and behaviors during pregnancy. J Am Diet Assoc 103: 1314-1319.

16. Skouteris H1, Carr R, Wertheim EH, Paxton SJ, Duncombe D (2005) A prospective study of factors that lead to body dissatisfaction during pregnancy. Body Image 2: 347-361.

17. Walker LO1, Cooney AT, Riggs MW (1999) Psychosocial and demographic factors related to health behaviors in the 1st trimester. J Obstet Gynecol Neonatal Nurs 28: 606-614.
18. Bartosíková Z1, Tyrlík M (2002) [Perception of changes in body weight during pregnancy]. Ceska Gynekol 67: 65-71.

19. Boscaglia N1, Skouteris H, Wertheim EH (2003) Changes in body image satisfaction during pregnancy: a comparison of high exercising and low exercising women. Aust N Z J Obstet Gynaecol 43: 41-45.

20. Zwelling E (1007) Psychological responses to pregnancy. Maternalnewborn nursing theory and practice. U.S.A.: W.B. Saunders Comp.

21. Jayasvasti K1, Kanchanatawan B (2005) Happiness and related factors in pregnant women. J Med Assoc Thai 88 Suppl 4: S220-225.

22. Strang VR, Sullivan PL (1985) Body image attitudes during pregnancy and the postpartum period. J Obstet Gynecol Neonatal Nurs 14: 332-337.

23. Fox P1, Yamaguchi C (1997) Body image change in pregnancy: a comparison of normal weight and overweight primigravidas. Birth 24 : 35-40.

24. Karanisoglu H (1996) Pregnancy and nursing care. Nursing of delivery and women diseases. I. Edition, Eskisehir.

25. Tulman L1, Morin KH, Fawcett J (1998) Prepregnant weight and weight gain during pregnancy: relationship to functional status, symptoms, and energy. J Obstet Gynecol Neonatal Nurs 27: 629-634.

26. Komürcü N (2000) Pre-natal period and its problems. Nursing of delivery and women diseases handbook. Vehbi Koc Foundation Publications, Istanbul.

27. Taskin L (2004) Nursing of delivery and women diseases. II. Enlarged Edition, Ankara.

28. Güler C (1989) Pregnancy. Mother health and family-planning. Hatipoglu Publishing House, II. Edition, Ankara

29. Davis DC (1996) The discomforts of pregnancy. J Obstet Gynecol Neonatal Nurs 25: 73-81.

30. Goodwin A1, Astbury J, McMeeken J (2000) Body image and psychological well-being in pregnancy. A comparison of exercisers and non-exercisers. Aust N Z J Obstet Gynaecol 40: 442-447.

31. Koken G (2007) Yilmazer M. Pregnancy and exercise. Turkiye Klinikleri J Gynecol Obs 17:385-392.

32. Y SC (1994) [Analysis of the quality of special charts]. Zhonghua $\mathrm{Hu} \mathrm{Li}$ Za Zhi 29: 14-15. 